\title{
THE FEATURES OF STRUCTURAL-PHASE TRANSFORMATIONS IN THE 12Kh18N10T STAINLESS STEEL SUBJECTED TO HIGH-FREQUENCY HYDRODYNAMIC EFFECTS UNDER HIGH PRESSURE
}

\author{
V. G. Pushin ${ }^{1,2^{*}}$, E. Yu. Muryshev ${ }^{3}$, E. S. Belosludtseva ${ }^{1}$, N. N. Kuranova ${ }^{1}$, \\ A. V. Pushin ${ }^{1}$, A. E. Svirid ${ }^{1}$, A. N. Uksusnikov ${ }^{1}$ \\ ${ }^{1}$ M.N. Miheev Institute of Metal Physics, Ural Branch of the Russian Academy of Sciences, \\ 18 S. Kovalevskoy St., Ekaterinburg, Russia \\ ${ }^{2}$ B.N. Yeltsin Ural State University, 19 Mira St., Ekaterinburg, Russia \\ ${ }^{3}$ Sole Proprietor Muryshev E.Yu., Moscow, Russia \\ *Corresponding author. E-mail: pushin@imp.uran.ru \\ Address for correspondence: 18 S. Kovalevskaya Street, Yekaterinburg, Russian Federation, 620108 \\ Tel.: 834337835 32; fax: 83433745244
}

For the first time, transmission electron microscopy is applied to the study of stainless steel specimens subjected to prolonged high-frequency $(50 \mathrm{MHz})$ external hydrodynamic effects (EHDE) under high pressure $(2-3 \mathrm{GPa})$ in a device of special design. It is found that, due to EHDE, the solid surface layer of the steel, up to $100 \mu \mathrm{m}$ thick, undergoes a strain-induced martensitic transformation with the appearance of a finely twinned $\beta$ - and $\varepsilon$-phase crystal structure. In the following intermediate layers located at a depth of 100 to $200 \mu \mathrm{m}$, traces of fragmentation with a dislocation and twinned substructure inside the austenite grains are found, which are caused by work hardening of austenite in the process of direct and reverse $\gamma-\varepsilon-\beta$ martensitic transformation. The features of $\gamma$-austenite, $\varepsilon$ - and $\beta$-martensite microstructures are studied in detail. It is concluded from the analysis of the obtained and known data that thermo-, baroand elastic-plastic mechanisms of martensitic transformations take place under multicycle highfrequency external effects. The martensitic transformation must be accompanied by baro- and magnetocaloric exothermal effects, by direct martensitic transformation and, consequently, endothermic effects during reverse transformation.

Keywords: stainless steel, martensite, substructure, twins, reverted austenite, thermo-, baroand magnetocaloric effects

\section{Acknowledgement}

The work was done within state assignment for IMP UB RAS (theme "Structure"), with the support from UB RAS, project 15-9-2-17, and Sole Proprietor Muryshev E. Yu.

DOI: $10.17804 / 2410-9908.2017 .4 .052-060$

\section{References}

1. Kurdyumov G.V., Utevsky L.M., Etin E.I. Prevrashcheniya v zheleze $i$ stalyakh [Transformations in Iron and Steels]. Moscow, Nauka Publ., 1977, 236 p. (In Russian).

2. Sagaradze V.V., Uvarov A.I. Uprochnenie $i$ svoystva austenitnykh staley [Hardening and Properties of Austenitic Steels]. Ekaterinburg, UB RAS Publ., 2013, 720 p. (In Russian).

3. Pushin V.G., Kondratiev V.V., Khachin V.N. Predperekhodnye yavleniya i martensitnye prevrashcheniya [Pretransitional Phenomena and Martensitic Transformations]. Ekaterinburg, UB RAS Publ., 1998, 368 p. (In Russian).

4. Lobodyuk V.A., Estrin E.I. Martensitnye yavleniya [Martensitic Transformations]. Moscow, Fizmatlit Publ., 2009, 352 p. (In Russian).

5. N. Resnina, V. Rubanik, eds. Shape Memory Alloys: Properties, Technologies, Opportunities, Trans Tech Publications, 2015, 640 p. 
6. Lobodyuk V.A., Koval' Yu.N., Pushin V.G. Crystal-structural features of pretransition phenomena and thermoelastic martensitic transformations in alloys of non-ferrous metals. The Physics of Metals and Metallography, 2011, vol. 111, no. 2, pp. 165-189. DOI: 10.1134/S0031918X11010212.

7. Panchenko E.Yu., Chumlyakov Yu.I., Surikov N.Yu., Maier H.J., Gerstein G., Sehitoglu N. Superelasticity in high-strength heterophase single crystals of $\mathrm{Ni}_{51.0} \mathrm{Ti}_{36.5} \mathrm{Hf}_{12.5}$ alloy. Technical Physics Letters, 2015, vol. 41, no. 8, pp. 797-800. DOI: 10.1134/S1063785015080283.

8. Resnina N., Belyaev S., Shelyakov A. Martensitic transformation in amorphous-crystalline $\mathrm{Ti}-\mathrm{Ni}-\mathrm{Cu}$ and Ti-Hf-Ni-Cu thin ribbons. Eur. Phys. J. Special Topics, 2008, vol. 158, pp. 21-26. DOI: 10.1140/epjst/e2008-00648-4.

9. Pushin V.G., Pushin A.V., Kuranova N.N., Kuntsevich T.E., Uksusnikov A.N., Dyakina V.P., Kourov N.I. Thermoelastic martensitic transformations, mechanical properties, and shape-memory effects in rapidly quenched $\mathrm{Ni}_{45} \mathrm{Ti}_{32} \mathrm{Hf}_{18} \mathrm{Cu}_{5}$ alloy in the ultrafine-grained state. The Physics of Metals and Metallography, 2016, vol. 117, no. 12, pp. 1261-1269. DOI: $10.1134 / \mathrm{S} 0031918 \mathrm{X} 16120115$.

10. Pushin V.G., Muryshev E.Yu., Belosludtseva E.S., Kuranova N.N., Pushin A.V., Svirid A.E., Uksusnikov A.N., Ananev A.I., Shevchenko V.G. The effect of high frequency hydrodynamic expusre of on structural high pressure and phase transformations in stainless steel 12X18H10T. Fundamental research, 2017, no. 9-2, pp. 351-356. (In Russian).

11. Uspekhi fiziki metallov, A. L. Roitburd, transl. Moscow, Metallurgizdat Publ., 1961, vol. 4, pp. 192-269 [Kaufman L. and Cohen M. Thermodynamics and kinetics of martensitic transformations. In: Progress in Metal Physics, B. Chalmers and R. King, eds., Pergamon Press, New York, 1958, vol. 7, pp. 165-246]. (In Russian). 
Подана в журнал: 07.07.2017

УДК 691.714

DOI: $10.17804 / 2410-9908.2017 .4 .052-060$

\title{
ОСОБЕННОСТИ СТРУКТУРНО-ФАЗОВЫХ ПРЕВРАЩЕНИЙ В НЕРЖАВЕЮЩЕЙ СТАЛИ 12Х18Н10Т, ПОДВЕРГНУТОЙ ВЫСОКОЧАСТОТНОМУ ГИДРОДИНАМИ- ЧЕСКОМУ ВОЗДЕЙСТВИЮ ПОД ВЫСОКИМ ДАВЛЕНИЕМ
}

\author{
В. Г. Пушин ${ }^{1,2 *}$, Е. Ю. Мурышев ${ }^{3}$, Е. С. Белослудцева ${ }^{1}$, Н. Н. Куранова ${ }^{1}$, \\ А. В. Пушин ${ }^{1}$, А. Э. Свирид ${ }^{1}$, А. Н. Уксусников ${ }^{1}$ \\ ${ }^{1}$ Институт физики металлов им. М.Н. Михеева УрО РАН, ул. С. Ковалевской 18, Екатеринбург, Россия \\ ${ }^{2}$ Уральский федеральный университет, ул. Мира 19, Екатеринбург, Россия \\ ${ }^{3}$ ИП Мурышев Е.Ю., Москва, Россия \\ *Ответственный автор. E-mail: pushin@imp.uran.ru \\ Адрес для переписки: 620108, г. Екатеринбург, ул. С. Ковалевской 18 \\ Тел.: 8(343)378-35-32; факс: 374-52-44
}

Впервые исследования методом просвечивающей электронной микроскопии выполнены в образцах нержавеющей стали, подвергнутых длительному высокочастотному (50 МГц) гидродинамическому внешнему воздействию (ВГДВ) под высоким давлением (2-3 ГПа) в устройстве специальной конструкции. Обнаружено, что при ВГДВ в сплошном приповерхностном слое стали толщиной до 100 мкм образуется структура, сформированная деформационно-индуцированными тонкодвойникованными кристаллами альфа и эпсилон фаз. В следующем промежуточном слое, расположенном на глубине 100-200 мкм, внутри аустенитных зерен найдены следы фрагментации с дислокационной и двойникованной субструктурой, обусловленные фазовым наклепом ревертированного аустенита в процессе прямого и обратного мартенситного превращения гамма-эпсилон-альфа. Особенности микроструктуры гамма-аустенита, эпсилон- и альфа-мартенсита детально изучены. Анализ полученных и известных данных показал, что при указанном многоцикловом высокочастотном внешнем воздействии имели место термо-, баро- и упругопластические механизмы реализации данных мартенситных превращений.

Ключевые слова: нержавеющая сталь, мартенсит, субструктура, двойники, ревертированный аустенит, термо-, баро-, магнитокалорический эффект

\section{1. Введение}

Высокие прочностные свойства конструкционных металлических материалов обеспечиваются за счет использования диффузионно-контролируемых фазовых превращений (прежде всего распада пересыщенных твердых растворов и эвтектоидного распада) и бездиффузионных мартенситных превращений, реализующихся по деформационному механизму $[1,2]$. Они являются одними из наиболее широко распространенных фазовых превращений первого рода в сталях и сплавах. За счет механического двойникования и мартенситного превращения в процессе деформации могут быть достигнуты высокие пластические свойства $[2,3]$. При этом за высокую пластичность ответственны те же деформационные структурно-фазовые превращения (механическое двойникование и мартенситное превращение), но возникающие в локальных концентраторах пиковых напряжений. Поскольку пластическое течение переходит эстафетно в соседние микрообъемы (или зернах) аустенита, при механических испытаниях или эксплуатации изделий исключается преждевременная локализация пластической деформациии, как следствие, разрушение. 
Термо- или механоиндуцированные мартенситные превращения возможны не только в сталях, но и во многих цветных металлах, сплавах и интерметаллических соединениях [2-4]. Если они имеют высокообратимый термоупругий или механоупругий механизмы, то сплавы демонстрируют так называемые эффекты памяти формы [3-5]. Необходимыми условиями возникновения эффектов памяти формы (одно- или многократно обратимой памяти формы, сверхупругости, сверхпластичности и др.) являются наличие размягчения модулей упругости и особого, кристаллографически высокообратимого в данных материалах механизма деформации по мартенситному типу, происходящего за счет обратимой кооперативной перестройки атомно-кристаллической решетки и аккомодационного механического двойникования при прямом и обратном фазовых переходах или сдвиговой переориентации кристаллов мартенсита под нагрузкой в межкритическом интервале температур [3, 6, 7]. Применяя различные системы легирования, режимы термических и термомеханических обработок, в том числе специальные экстремальные внешние воздействия [7-9], можно управлять обратимостью и температурно-деформационными интервалами реализации мартенситных превращений [6-8]. Кроме того, возможно изменять нетермоупругие механизмы мартенситного превращения в термоупругие или, наоборот, термоупругие в нетермоупругие в одних и тех же сплавах $[2,3]$.

\section{2. Материал и методика}

В работе впервые, используя методы аналитической просвечивающей электронной микроскопии и микродифракции электронов, была изучена нержавеющая сталь $12 \mathrm{X} 18 \mathrm{H} 10 \mathrm{~T}$ в исходном закаленном состоянии и после длительной (до 1 года) обработки мощным высокочастотным (с частотой 50 МГц) гидродинамическим внешним воздействием (ВГДВ) высокоскоростным потоком жидкости (воды) со скоростью (25-30) м/с, обеспечивающим его высокое давление (2-3) ГПа в аппарате специально разработанной конструкции из тонких колец стали 12Х18Н10Т, чередующихся по диаметру.

Структурные исследования проводили на оборудовании ЦКП ИФМ УрО РАН. Для изучения структурно-фазовых изменений в тонких приповерхностных слоях стали необходимо было тщательно приготовить тонкие образцы для просвечивающей электронной микроскопии. Это достигалось их электролитическим утонением с внутренней стороны образцов, первоначально вырезанных из заготовки стали электро-эрозионным методом и подвергнутой шлифованию следов резки. Поверхностный слой заготовки, на которой осуществлялось или не осуществлялось ВГДВ, предварительно защищался от электролитического воздействия при утонении.

\section{3. Результаты экспериментов}

На рис. 1 а приведено полученное методом просвечивающей электронной микроскопии типичное изображение обычной зеренной структуры $\gamma$-аустенита в поперечных сечениях (cross-section) исследуемых стальных кольцевых образцов в исходном состоянии. Методом просвечивающей электронной микроскопии в приповерхностном слое стали после ВГДВ

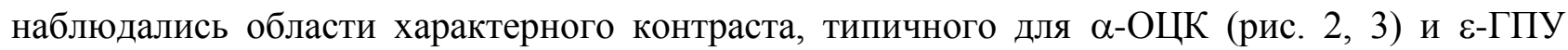
(рис. 4) тонкопластинчатого мартенсита, возникающих в исследуемой стали при ВГДВ. На изображениях, представленных на рис. 2-4, отчетливо идентифицируется высокодефектная тонкодвойникованная пакетная морфология $\varepsilon-$ и $\alpha$-мартенсита, содержащих также высокую плотность дислокаций. Типичной для промежуточного слоя, залегающего на глубине (100-200) мкм от края кольца была фрагментированная ячеистая субструктура, содержащая несколько повышенную плотность двойниковых границ (рис. 1 в) и дислокаций (рис. 1 б, г), что характерно для фазонаклепанного $\gamma$-аустенита. По данным элементного микроанализа, в указанных приповерхностных слоях химический состав не изменился. 


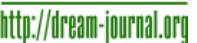

Магнитометрические исследования при комнатной температуре показали, что в приповерхностном слое после ВГДВ содержались ферромагнитная $\alpha$-фаза и антиферромагнитная $\varepsilon$-фаза. Оценка их количества в сплошном слое толщиной до 100 мкм отвечает определенному при измерениях суммарному объему ферромагнитной фазы $(0,3-0,5$ \%). По данным низкотемпературных магнитных измерений при охлаждении, в стали мартенситное превращение продолжилось ниже температуры $\mathrm{M}_{\mathrm{s}}$, близкой минус $210{ }^{\circ} \mathrm{C}$. Это согласуется с известными сведениями [2]. Количество антиферромагнитной фазы $\varepsilon$-мартенсита увеличивалось в интервале между комнатной температурой и $\mathrm{M}_{\mathrm{s}}$, устанавливая таким образом последовательное протекание $\gamma \rightarrow \varepsilon \rightarrow \alpha$ мартенситных превращений при охлаждении.
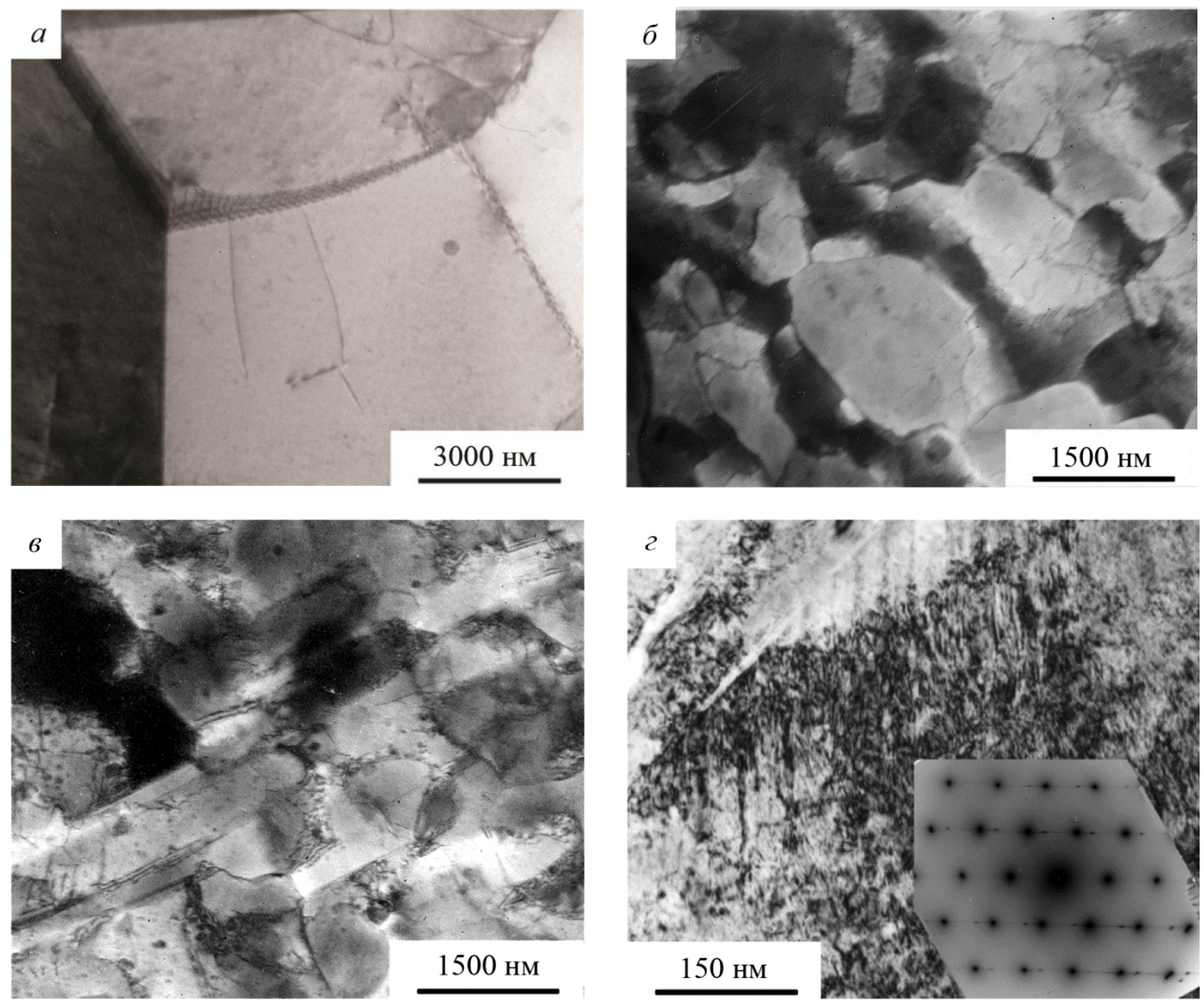

Рис. 1. Изображения $(a-2)$ и соответствующая микроэлектронограмма (вставка на рис. г), полученныеметодом просвечивающей электронной микроскопии, закаленной стали

$12 \mathrm{X} 18 \mathrm{H} 10 \mathrm{~T}$ в исходном состоянии $(a)$ и после ВГДВ в течение 1 года промежуточном слое 100-200 мкм (б-2) 
nttp:///ream-journal.or"]
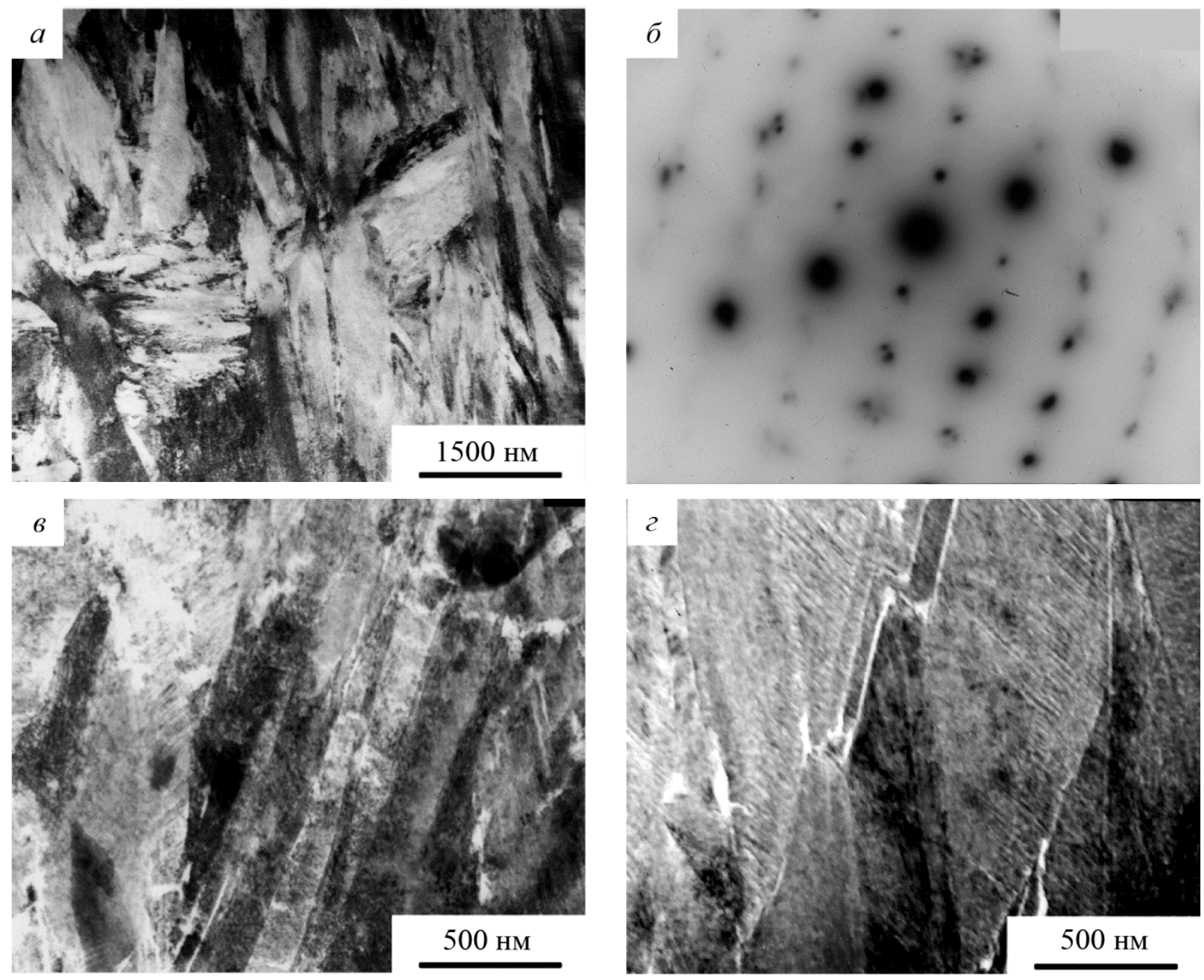

Рис. 2. Изображения, полученные методом просвечивающей электронной микроскопии, дислокационного $\alpha$-мартенсита пакетной двойниковой морфологии $(a, b, 2)$ и соответствующая электронограмма (б, ось зоны [110] ОЦК) в приповерхностном слое после ВГДВ в течение 1 года
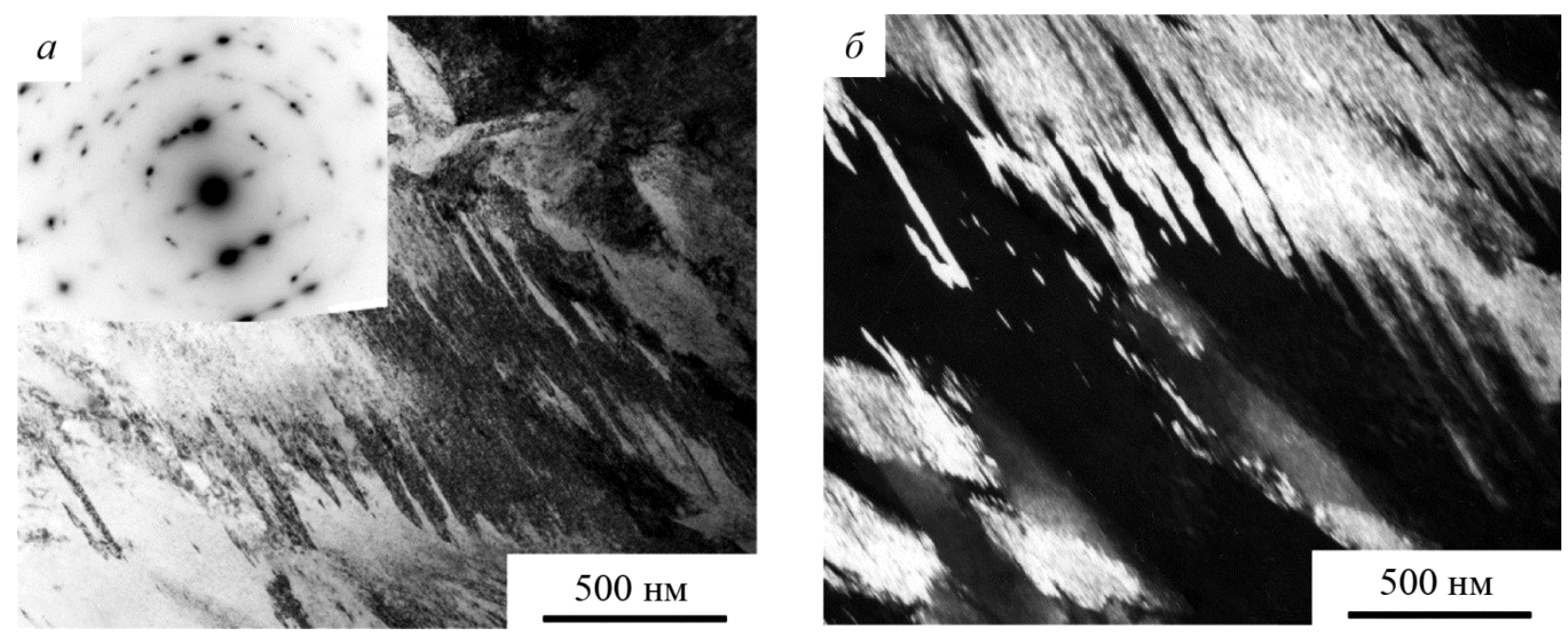

Рис. 3. Светло- $(a)$ и темнопольное (б) изображения и соответствующая микроэлектронограмма (вставка на рис. $a$ ), полученные методом просвечивающей электронной микроскопии, тонкодвойникованного $\alpha$-мартенсита пакетной морфологии в приповерхностном слое после ВГДВ в течение 1 года

Pushin V.G. et al. / The features of structural-phase transformations in the 12Kh18N10T stainless steel subjected to high-frequency hydrodynamic effects under high pressure 

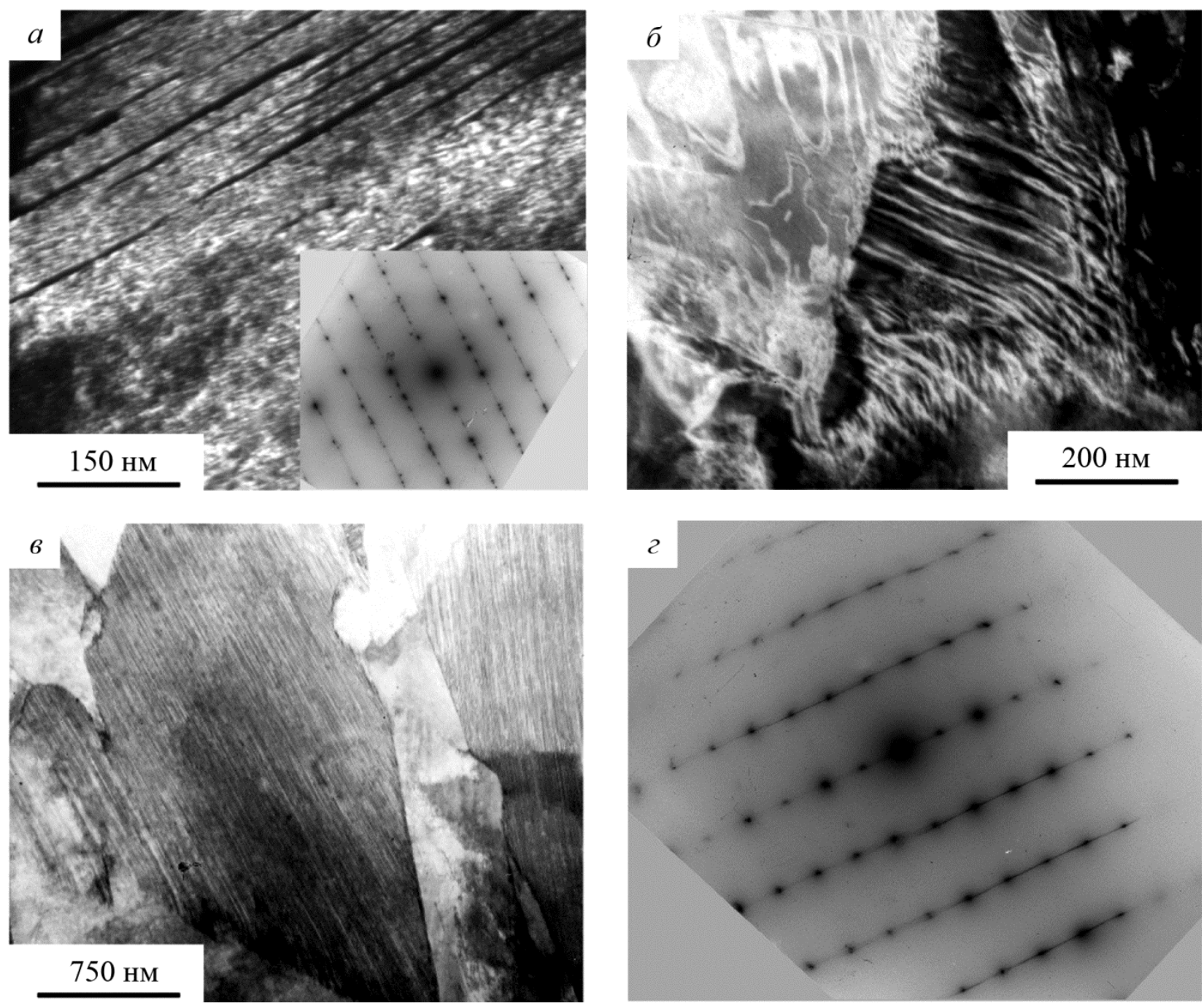

Рис. 4. Темно- $(a, \sigma)$ и светлопольное $($ ( $)$ изображения и соответствующие электронограммы

(2, вставка на рис. $a$ ), полученные методом просвечивающей электронной микроскопии механических нанодвойников в аустените $(a)$, изогнутых (б) и прямолинейных (в) тонких двойников в $\varepsilon$-мартенсите пакетной морфологии и в приповерхностном слое после ВГДВ в течение 1 года

При рентгеноструктурном анализе при комнатной температуре было выявлено наличие ОЦК-фазы в вогнутых приповерхностных слоях колец, подвергнутых ВГДВ. В остальных приповерхностных слоях образцов (в том числе в поперечных сечениях) была идентифицирована только ГЦК-фаза - $\gamma$-аустенита.

\section{4. Обсуждение результатов}

Как известно, в метастабильных сталях и сплавах железа, включая нержавеющие стали типа 12X18Н10Т, происходят при охлаждении и в процессе пластической деформации бездиффузионные мартенситные превращения по различным вариантам $\gamma \rightarrow \alpha, \gamma \rightarrow \varepsilon, \gamma \rightarrow \varepsilon \rightarrow \alpha$ [1-3]. Уже отмечалось, что если механическое двойникование и мартенситные превращения в сталях вызывает деформация, это может приводить к эффектам повышения их пластичности. Данные процессы приводят к повышению плотности дислокаций и механических нанодвойников и измельчению кристаллов мартенситных фаз [3]. Важно, что стабильность полученных микроструктуры и фазового состава таких сталей сохраняется в достаточно широком (до 500) ${ }^{\circ} \mathrm{C}$ межкритическом температурном интервале (вплоть до температуры ре-

Pushin V.G. et al. / The features of structural-phase transformations in the 12Kh18N10T stainless 
кристаллизации аустенита) [1-3]. В сплавах с термоупругим, бароупругим, механоупругим или магнитоупругим механизмами мартенситного превращения фазовый состав при циклировании температуры, величины давления или магнитного поля, превышающих критические уровни, будет радикально изменяться в гораздо более узком межкритическом интервале, характеризуясь их высокой фазовой, ориентационно-текстурной и микроструктурноморфологической обратимостью [3, 4].

На основании проведенных в работе электронномикроскопических и рентгеноструктурных исследований впервые сделан вывод, что в изученной стали, подвергнутой ВГДВ в условиях достигаемых экстремальных внешних воздействий, происходило термо-, барои магнитоупругое мартенситное превращение при температурах, более чем на $200{ }^{\circ} \mathrm{C}$ превышающих $\mathrm{M}_{\mathrm{S}}$. Как известно, при ударном сжатии давление на фронте ударной волны быстро возрастает, а в волне разрежения давление становится отрицательным, т. е. сжимающие напряжения сменяются растягивающими. При этом очевидно, что в метастабильном аустените в областях сжатия (и уменьшения объема) будет стимулироваться зарождение и упругий рост кристаллов пластин $\varepsilon$-фазы, а в областях растяжения (увеличения объема) - рост $\alpha$-фазы. ВГДВ жидкостью высокого давления осуществлялось с большой частотой и не одновременно в приповерхностном слое в различных участках внутренних поверхностей колец нержавеющей стали, поэтому указанные баро- и деформационно-индуцированные (сдвиговые по атомному механизму) мартенситные превращения должны происходить обратимо и циклически по схемам: $\gamma \leftrightarrow \varepsilon, \gamma \leftrightarrow \alpha, \gamma \leftrightarrow \varepsilon \leftrightarrow \alpha$, обеспечивая взаимную аккомодацию объемных эффектов превращений (отрицательных по величине при $\gamma \rightarrow \varepsilon$ и положительных при $\gamma \rightarrow \alpha$ ) [2-4]. Прекращение ВГДВ зафиксировало в тонком наружном слое мартенситную структуру. Экспериментально была определена толщина слоя (до 100 мкм), в котором вследствие приповерхностной релаксации сохранился мартенсит и не испытал обратного превращения. В более глубоких прилегающих объемах, напротив, обратное мартенситное превращение завершилось, но остались следы фазового наклепа. Безусловно, что при реализации термо-, баро-, магнитоупругих механизмов при указанных превращениях будут осуществляться баро- и магнитокалорические эффекты $[4,10]$.

\section{5. Заключение}

В результате выполненных исследований нержавеющей стали после ВГДВ методом просвечивающей электронной микроскопии высокого разрешения и микродифракции электронов были обнаружены следующие структурно-фазовые изменения. ВГДВ в узком приповерхностном слое стали (толщиной до 100 мкм) привело к появлению деформационноиндуцированных тонкодвойникованных кристаллов мартенситных ферромагнитной $\alpha$ и антиферромагнитной $\varepsilon$ фаз. В следующем промежуточном слое (глубиной до 100 мкм) была обнаружена ячеистая фрагментация с повышенной плотностью дислокаций и микродвойников внутри аустенитных зерен, указывающая на деформационно-фазовый наклеп $\gamma$-аустенита. Полученные результаты доказывают, что в исследованных приповерхностных областях стали происходило обратимое мартенситное превращение. Но если в областях сжатия стали мощным ВГДВ стимулируется зарождение и квазиупругий рост пластин $\varepsilon$-фазы, то в областях растяжения - кристаллов $\alpha$-фазы. Поскольку ВГДВ под высоким давлением происходило длительное время (1 год) и с большой частотой, деформационно-индуцированные, сдвиговые по механизму мартенситные превращения реализовывались многократно и циклически по схемам: $\gamma \leftrightarrow \varepsilon, \gamma \leftrightarrow \alpha, \gamma \leftrightarrow \varepsilon \leftrightarrow \alpha$ в условиях взаимной аккомодации объемных эффектов превращений. Прекращение ВГДВ привело к наследованию в тонком наружном слое мартенситной структуры вследствие приповерхностной релаксации. Его толщина по экспериментальным данным составила до 100 мкм. В более глубоких внутренних объемах обратное мартенситное превращение успело состояться. Следствием реализации особых термо-, баро-, магнитоупругих механизмов указанных превращений будет осуществление баро- 
и магнитокалорических эффектов. Их заметная асимметрия по величине в циклах прямого и обратного структурно-фазовых превращений может стать причиной, например, значительного устойчивого тепловыделения («теплового насоса») в аппаратах, вызывающих данные превращения в результате чего механическая энергия преобразуется в тепловую.

\section{Благодарность}

Работа выполнена в рамках Госзадания ИФМ УрО РАН (по теме «Структура»), при поддержке проектом УрО РАН № 15-9-2-17 и ИП Е.Ю. Мурышев.

\section{Список литературы}

1. Курдюмов Г. В., Утевский Л. М., Этин Э. И. Превращения в железе и стали. М. : Наука, 1977. - 236 с.

2. Сагарадзе В. В., Уваров А. И. Упрочнение и свойства аустенитных сталей. Екатеринбург : РИО УрО РАН, 2013. - 720 с.

3. Пушин В. Г., Кондратьев В. В., Хачин В. Н. Предпереходные явления и мартенситные превращения. - Екатеринбург : УрО РАН, 1998. - 368 с.

4. Лободюк В. А., Эстрин Э. И. Мартенситные превращения. - М. : Физматлит, 2009. -352 c.

5. Shape Memory Alloys: Properties, Technologies, Opportunities / ed. by N. Resnina and V. Rubanik. - Zurich: Trans Tech Publications, 2015. - 640 p.

6. Lobodyuk V. A., Koval' Yu. N., Pushin V. G. Crystal-structural features of pretransition phenomena and thermoelastic martensitic transformations in alloys of non-ferrous metals // The Physics of Metals and Metallography. - 2011. - Vol. 111, no. 2. - P. 165-189. DOI: $10.1134 /$ S0031918X11010212.

7. Superelasticity in high-strength heterophase single crystals of $\mathrm{Ni}_{51.0} \mathrm{Ti}_{36.5} \mathrm{Hf}_{12.5}$ alloy / E. Yu. Panchenko, Yu. I. Chumlyakov, N. Yu. Surikov, H. J. Maier, G. Gerstein, N. Sehitoglu // Technical Physics Letters. - 2015. - Vol. 41, no. 8. - P. 797-800. - DOI: 10.1134/S1063785015080283.

8. Resnina N., Belyaev S., Shelyakov A. Martensitic transformation in amorphous-crystalline $\mathrm{Ti}-\mathrm{Ni}-\mathrm{Cu}$ and Ti-Hf-Ni-Cu thin ribbons // Eur. Phys. J. Special Topics. - 2008. - Vol. 158. P. 21-26. - DOI: 10.1140/epjst/e2008-00648-4.

9. Thermoelastic martensitic transformations, mechanical properties, and shape-memory effects in rapidly quenched $\mathrm{Ni}_{45} \mathrm{Ti}_{32} \mathrm{Hf}_{18} \mathrm{Cu}_{5}$ alloy in the ultrafine-grained state / V. G. Pushin, A. V. Pushin, N. N. Kuranova, T. E. Kuntsevich, A. N. Uksusnikov, V. P. Dyakina, N. I. Kourov // The Physics of Metals and Metallography. - 2016. - Vol. 117, no. 12. - P. 1261-1269. DOI: 10.1134/S0031918X16120115.

10. Влияние высокочастотного воздействия под высоким давлением на структурнофазовые превращения в нержавеющей стали 12Х18Н10T / В. Г. Пушин, Е. Ю. Мурышев, Е. С. Белослудцева, Н. Н. Куранова, А. В. Пушин, А. Э. Свирид, А. Н. Уксусников, А. И. Ананьев, В. Г. Шевченко // Фундаментальные исследования. - 2017. - № 9-2. C. 351-356.

11. Кауфман Л., Коэн М. Термодинамика и кинетика мартенситных превращений / пер. с англ. А. Л. Ройтбурда // Успехи физики металлов. - М. : Металлургиздат, 1961. T. 4. - C. 192. 